\title{
PENGARUH KONSENTRASI BAP TERHADAP MULTIPLIKASI TUNAS ANTHURIUM (Anthurium andraeanum Linden) PADA BEBERAPA MEDIA DASAR SECARA IN VITRO
}

\section{THE EFFECT OF BAP CONCENTRATION OF ANTHURIUM'S (Anthurium andraeanum Linden) SHOOT MULTIPLICATION ON SOME NUTRIENT MEDIUMS BY IN VITRO}

\author{
Endang Yuniastuti, Praswanto, Ika Harminingsih \\ Fakultas Pertanian UNS jurusan Agroteknologi
}

\begin{abstract}
ABSTRAK
Penelitian bertujuan untuk mengetahui pengaruh macam media tanam dan konsentrasi BAP (6Benzyl Amino Purine) terhadap multiplikasi tunas Anthurium secara in vitro. Perlakuan penelitian meliputi macam media tanam yang terdiri dari : medium Murashige dan Skoog (MS), Schenk dan Hildebrandt (SH) serta Nitsch dan Nitsch (N2) dan konsentrasi BAP terdiri dari : 0 ppm, 2 ppm, 4 ppm. Variabel pengamatan meliputi saat muncul tunas, jumlah tunas, panjang tunas, saat muncul daun, jumlah daun, saat muncul akar, panjang dan jumlah akar. Rancangan penelitian berupa Rancangan Acak Lengkap (RAL). Data yang didapat ditampilkan secara diskriptif dan uji $\mathrm{F}$ taraf $5 \%$, bila ada beda nyata dilanjutkan uji DMRT.

Hasil penelitian menunjukkan bahwa terjadi interaksi antara media dan konsentrasi BAP secara nyata pada jumlah dan panjang tunas. Medium N2 dengan penambahan 4 ppm BAP menunjukkan adanya jumlah tunas terbanyak dan tunas terpanjang. Medium MS tanpa penambahan BAP menunjukkan saat muncul tunas tercepat. Saat muncul daun tercepat pada perlakuan MS dengan 2 ppm BAP dan jumlah daun terbanyak ditunjukkan pada perlakuan medium SH tanpa penambahan BAP. Saat muncul akar tercepat pada perlakuan medium SH dengan 4 ppm BAP, sedangkan akar terpanjang ditunjukkan oleh perlakuan Medium N2 tanpa penambahan BAP.
\end{abstract}

Kata Kunci : Anthurium andraeanum, BAP, nutrisi media, in vitro

\begin{abstract}
The aim of the research is to understand the effect of nutrient mediums and BAP (6-Benzyl Amino Purine) concentration of Anthurium andraeanum's shoot multiplication by in vitro. This propagation method is done by planting a single node of this plant to the nutrient medium, then taken care up to 12 weeks since it was planted.

The treatments are the nutrient mediums, those are Murashige and Skoog (MS), Schenk and Hildebrandt (SH), and Nitsch and Nitsch (N2), then the concentration of BAP, consist of 0 ppm, 2 ppm,and 4 ppm. The variabel observed contain : first appearance of bud, number of bud, length of bud, first appearance of leaf, number of leaf, first appearance of root and number of root. This research using Completely Randomized Design and the data showed by discriptive and F test level 5\%. When significant got, the data tested on DMRT (Duncan Multiple Range Test).

The result showed that there was significantly interaction between medium and BAP concentration on the sum of bud and height of bud. N2 medium with 2 ppm BAP give highest number of bud and longest bud formation. MS medium without BAP give the fastest of first appearance of bud. The fastest of first appearance of leaf given by MS medium with 2 ppm BAP then, biggest sum of leaf showed by treatment using SH medium without adding of BAP. The fastest of first appearance of root given by SH medium with 4 ppm BAP, and longest root given by $N 2$ medium without BAP.
\end{abstract}

Keywords: Anthurium andraeanum, BAP, nutrient medium, in vitro 


\section{PENDAHULUAN}

Setiap manusia pada hakikatnya mempunyai perasaan estetis, yakni ketertarikan pada keindahan. Dalam kehidupan sehari-hari, perasaan estetis ini dapat tercermin antara lain lewat rangkaian bunga potong. Ragam jenis bunga yang dirangkai indah sebagai hiasan dapat memberi kebahagiaan bagi pemiliknya.

Selain sebagai hiasan, bunga potong merupakan bisnis yang menjanjikan bagi para pelakunya. Selama ini, pengembangan bisnis bunga di Indonesia untuk dijual ke pasar dunia masih terbuka luas. Salah satu jenis bunga potong yang berpotensi diekspor adalah Anthurium andraeanum (Anthurium bunga). Melalui kemajuan pemuliaan florikultura, kini telah dihasilkan berbagai jenis Anthurium hibrida yang rajin berbunga.

Anthurium dapat diperbanyak secara vegetatif dan generatif. Secara vegetatif dengan setek batang dan menanam anakan. Sedangkan perbanyakan secara generatif dengan biji. Sayangnya, perbanyakan secara konvensional mempunyai banyak kendalanya. Kendala-kendala tersebut yakni memakan waktu yang cukup lama (Rukmana, 1997), pertumbuhan tidak seragam, dan perbanyakan melalui setek batang tidak mencukupi untuk perbanyakan masal (Prihatmani dan Mattjik, 2004). Karena hal-hal tersebut maka perlu dicari cara perbanyakan Anthurium untuk menghasilkan bibit yang seragam, banyak dan cepat.

Salah satu upaya yang dilakukan untuk menghasilkan bibit yang seragam, cepat dan waktu yang relatif singkat adalah teknik kultur jaringan (in vitro). Menurut Marlina (2004) kultur jaringan merupakan salah satu teknik perbanyakan alternatif pada tanaman Anthurium, karena pembiakan Anthurium melalui cara konvensional tidak dapat diharapkan untuk memenuhi permintaan konsumen.

Media kultur merupakan salah satu faktor penentu keberhasilan perbanyakan tanaman secara kultur jaringan. Berbagai komposisi media kultur telah diformulasikan untuk mengoptimalkan pertumbuhan dan perkembangan tanaman yang dikulturkan. Dalam media kultur jaringan diperlukan penambahan zat pengatur tumbuh untuk mendukung pertumbuhan eksplan. Salah satu zat pengatur tumbuh yang sering digunakan adalah zat pengatur tumbuh yang berasal dari kelompok sitokinin. Menurut Badriah et al. (1998), sitokinin berpengaruh terhadap inisiasi tunas. Jenis sitokinin yang yang paling sering dipakai adalah 6-Benzyl Amino
Purine (BAP) karena efektivitasnya tinggi (Yusnita, 2003). Namun belum diketahui media tanam yang sesuai serta konsentrasi BAP yang mampu meningkatkan multiplikasi tunas Anthurium.

Penelitian ini bertujuan untuk mengetahui pengaruh macam media tanam dan konsentrasi BAP terhadap multiplikasi tunas Anthurium (Anthurium andraeanum Linden) secara in vitro. Dari penelitian ini akan diketahui media tanam dan konsentrasi BAP yang tepat untuk multiplikasi tunas Anthurium.

\section{METODE PENELITIAN}

Bahan yang digunakan dalam penelitian ini adalah tunas aksiler Anthurium andraeanum Linden, media MS (Murashige dan Skoog), N2 (Nitsch dan Nitsch), SH (Schenk dan Hildebrand), agar (pemadat), zat pengatur tumbuh BAP (6-Benzyl Amino Purine),

Penelitian ini menggunakan Rancangan Acak Lengkap (RAL) yang disusun secara faktorial terdiri dari 2 faktor, yakni media tanam dan konsentrasi BAP. Faktor pertama adalah media tanam, meliputi media Murashige dan Skoog, media Nitsch dan Nitsch, dan media Schenk dan Hildebrandt. Faktor kedua adalah konsentrasi BAP (6-Benzyl Amino Purine) meliputi 0 ppm, 2ppm, 4 ppm. Masing-masing perlakuan diulang 3 kali.

\section{HASIL DAN PEMBAHASAN}

\section{Saat Muncul Tunas}

Dari hasil analisis sidik ragam (Lampiran 2b) didapatkan bahwa dari perlakuan yang ada, baik perlakuan medium, konsentrasi BAP maupun interaksinya tidak memberi pengaruh yang berbeda nyata. Artinya, semua kombinasi perlakuan memberi saat kemunculan tunas yang hampir sama. Hal ini disebabkan karena media tanam yang digunakan serta 3 taraf konsentrasi BAP yang digunakan tidak memacu percepatan kemunculan tunas Anthurium.

Semakin meningkat konsentrasi BAP pada medium ini, saat muncul tunas semakin lama. Medium SH menunjukkan saat muncul tunas yang hampir bersamaan, yakni pada 5 MST. Medium N2 menunjukkan saat muncul tunas yang bervariasi. Pada 0 ppm BAP (tanpa penambahan BAP) tunas muncul pada 4,66 MST. Sedangkan pada penambahan 2 ppm BAP tunas muncul pada 5,66 MST, dan pada penambahan 4 ppm BAP kemunculan tunas justru lebih cepat, yakni 3 MST. Perkembangan eksplan dan 
pembentukan organ pada kultur in vitro disebabkan oleh kandungan nitrogen pada media dasar (Hoesen, 1998). Tunas, sebagai organ tanaman, pembentukan dan perkembangannya juga dipengaruhi oleh adanya nitrogen. Dalam kultur jaringan, nitrogen biasa ditambahkan dalam bentuk ammonium $\left(\mathrm{NH}_{4}{ }^{+}\right)$dan nitrat $\left(\mathrm{NO}_{3}{ }^{-}\right.$ ). Bila dilihat dari komposisi media, medium MS mempunyai kandungan nitrogen, baik dalam bentuk ammonium maupun nitrat yang lebih tinggi dibandingkan medium N2 dan medium SH

\section{Jumlah Tunas}

Dari Tabel 1 didapatkan bahwa jumlah tunas pada hampir semua perlakuan menunjukkan tidak berbeda nyata, kecuali perlakuan medium N2 dengan 4 ppm BAP. Medium N2 jika dibandingkan dengan medium MS dan SH kandungan unsur makronya, tergolong lebih rendah. Yakni pada kandungan $\mathrm{KNO}_{3}, \quad \mathrm{NH}_{4} \mathrm{NO}_{3}, \quad \mathrm{KH}_{2} \mathrm{PO}_{4}, \quad \mathrm{MgSO}_{4} .7 \mathrm{H}_{2} \mathrm{O}$. Walaupun demikian, dimungkinkan, kombinasi antara medium N2 dan konsentrasi BAP 4 ppm sangat mendukung terbentuknya jumlah tunas terbanyak, karena pertumbuhan eksplan pada kultur jaringan, dipengaruhi oleh media yang digunakan dan konsentrasi zat pengatur tumbuh (Hoesen, 1998).

Pertumbuhan eksplan sebagai indikasi keberhasilan kultur jaringan dipengaruhi oleh garam-garam mineral makro dan mikro pada media dasar dan konsentrasi zpt. Pada konsentrasi tinggi, sitokinin akan meningkatkan jumlah tunas yang terbentuk pada eksplan. Konsentrasi 4 ppm BAP pada medium N2 mampu mendorong bertambahnya tunas.

\section{Panjang Tunas}

Panjang tunas merupakan salah satu variabel penting dalam pengamatan multiplikasi tanaman. Tunas dengan nodus yang banyak, akan memberikan eksplan yang banyak dalam kegiatan subkultur. Hal tersebut disebabkan karena panjang tunas dipengaruhi oleh interaksi antara kedua perlakuan yaitu media tanam dan penambahan zat pengatur tumbuh BAP.

Tabel 2. Pengaruh media tanam dan konsentrasi BAP terhadap panjang tunas Anthurium hasil multiplikasi secara in vitro (transformasi $\sqrt{ }(\mathrm{x}+1 / 2))$

Dari hasil uji Duncan 5\%, seperti yang terlihat pada Tabel 2, perlakuan medium N2 dengan penambahan 4 ppm BAP memberikan rata-rata panjang tunas yang berbeda nyata dibandingkan perlakuan lain. Pada perlakuan medium MS dengan penambahan 2 ppm BAP juga memberikan rata-rata panjang tunas berbeda nyata, yakni $0,9 \mathrm{~cm}$. Panjang tunas ini melebihi rata-rata panjang tunas lainnya yang hanya berkisar antara $0,3 \mathrm{~cm}$ sampai dengan $0,8 \mathrm{~cm}$.

Perkembangan eksplan dan pembentukan organ pada kultur in vitro disebabkan oleh kandungan nitrogen pada media dasar. Nitrogen merupakan komponen protein, asam nukleat, dan substansi penting lainnya yang diperlukan untuk pembentukan protoplasma dan berfungsi memperbaiki pertumbuhan vegetatif (Widiastoety dan Kartikaningrum, 2003). Dari pernyataan tersebut, diduga kombinasi medium N2 dengan penambahan 4 ppm BAP merupakan kombinasi terbaik untuk memberikan tunas terpanjang pada Anthurium.

\section{Saat Muncul Daun}

Berdasar Tabel 3, kemunculan daun terdapat pada perlakuan medium MS dan medium SH. Sedangkan medium N2 sampai akhir pengamatan belum mampu memunculkan daun. Menurut Wetter dan Constabel (1991) medium MS mempunyai kandungan nitrat, kalium dan ammonium yang layak untuk untuk memenuhi kebutuhan banyak jenis sel tanaman dalam kultur in vitro.

Kandungan ini mempengaruhi diferensiasi, pertumbuhan dan perkembangan eksplan atau pembentukan organ pada eksplan (Hoesen, 1998). Hal itu disebabkan karena nitrogen merupakan komponen protein, asam nukleat, dan substansi penting lainnya yang diperlukan untuk pembentukan protoplasma dan berfungsi memperbaiki pertumbuhan vegetatif.

Medium SH juga mampu mendukung kemunculan daun. Menurut George dan Sherrington (1984) dan Gunawan (1988), medium SH cocok untuk kultur tanaman monokotil, termasuk didalamnya Anthurium. Adapun terhambatnya kemunculan daun pada medium N2 dimungkinkan karena kandungan nitrogen/bentuk senyawa nitrogen dan rasio antara ammonium dengan nitrat pada medium N2 belum dapat mempengaruhi terjadinya diferensiasi, pertumbuhan dan perkembangan eksplan atau pembentukan organ dengan cepat

Dari Tabel 3, kemunculan daun yang lebih cepat didapatkan pada perlakuan BAP 2 ppm pada media MS dan SH, yakni antara 5-7 MST. Saat kemunculan daun ini lebih cepat dibandingkan perlakuan 0 ppm (tanpa penambahan BAP) dan penambahan 4 ppm BAP yang memunculkan daun antara 7 sampai 11 MST. Perbandingan sitokinin yang lebih besar daripada auksin pada kultur in vitro akan 
menstimulasi pertumbuhan tunas dan daun. Sehingga diduga pada kultur in vitro Anthurium ini, konsentrasi 2 ppm BAP ini cukup optimal untuk mendukung pembentukan daun pada eksplan, sedangkan kenaikan konsentrasi BAP menjadi 4 ppm justru menghambat kemunculan daun.

Tabel 1. Pengaruh media tanam dan konsentrasi BAP terhadap jumlah tunas pada Anthurium hasil multiplikasi secara in vitro (transformasi $\sqrt{ }(\mathrm{x}+1 / 2)$ )

\begin{tabular}{lccc}
\hline \multirow{2}{*}{ Perlakuan } & \multicolumn{3}{c}{ Jumlah tunas } \\
\cline { 2 - 4 } & BAP 0 ppm & BAP 2 ppm & BAP 4 ppm \\
\hline Medium MS & $1,225 \mathrm{a}$ & $1,225 \mathrm{a}$ & $1,225 \mathrm{a}$ \\
Medium N2 & $1,225 \mathrm{a}$ & $1,360 \mathrm{a}$ & $3,115 \mathrm{~b}$ \\
Medium SH & $1,052 \mathrm{a}$ & $1,666 \mathrm{a}$ & $1,225 \mathrm{a}$ \\
\hline
\end{tabular}

Keterangan : angka yang diikuti huruf yang sama menunjukkan tidak berbeda nyata pada uji Duncan 5\%

Tabel 2. Pengaruh media tanam dan konsentrasi BAP terhadap panjang tunas Anthurium hasil multiplikasi secara in vitro (transformasi $\sqrt{ }(\mathrm{x}+1 / 2))$

\begin{tabular}{lccc}
\hline \multirow{2}{*}{ Perlakuan } & \multicolumn{3}{c}{ Panjang tunas } \\
\cline { 2 - 4 } & BAP 0 ppm & BAP 2 ppm & BAP 4 ppm \\
\hline Medium MS & $1,12 \mathrm{a}$ & $1,18 \mathrm{ab}$ & $0,93 \mathrm{a}$ \\
Medium N2 & $1,13 \mathrm{a}$ & $1,04 \mathrm{a}$ & $1,53 \mathrm{~b}$ \\
Medium SH & $1,09 \mathrm{a}$ & $1,01 \mathrm{a}$ & $0,98 \mathrm{a}$ \\
\hline
\end{tabular}

Keterangan : angka yang diikuti huruf yang sama menunjukkan tidak berbeda nyata pada uji Duncan 5\%

Tabel 3. Pengaruh media tanam dan konsentrasi BAP terhadap saat muncul daun Anthurium hasil multiplikasi secara in vitro

\begin{tabular}{ccccc}
\hline \multirow{2}{*}{ Media } & \multirow{2}{*}{ Ulangan } & \multicolumn{3}{c}{ Saat muncul daun } \\
\cline { 3 - 5 } & 1 & BAP 0 ppm & BAP 2 ppm & BAP 4 ppm \\
\hline MS & 1 & $11 \mathrm{MST}$ & - & - \\
MS & 2 & - & $7 \mathrm{MST}$ & - \\
MS & 3 & - & $5 \mathrm{MST}$ & - \\
MS & 2 & $7 \mathrm{MST}$ & - & $8 \mathrm{MST}$ \\
SH & 3 & - & - & - \\
SH & & & $6 \mathrm{MST}$ & - \\
\hline
\end{tabular}

Keterangan: MST : minggu setelah tanam ; ppm : part per million (mg/l) Tanda (-) : tidak memunculkan daun sampai 12 MST

Tabel 4. Pengaruh media tanam dan konsentrasi BAP terhadap jumlah daun Anthurium hasil multiplikasi secara in vitro

\begin{tabular}{ccccc}
\hline \multirow{2}{*}{ MEDIA } & \multirow{2}{*}{ ULANGAN } & \multicolumn{3}{c}{ Jumlah daun } \\
\cline { 3 - 5 } & & BAP 0 ppm & BAP 2 ppm & BAP 4 ppm \\
\hline MS & 1 & 2 & - & - \\
MS & 1 & - & 1 & - \\
MS & 2 & - & 1 & - \\
MS & 3 & - & - & 1 \\
SH & 2 & 3 & - & - \\
SH & 3 & - & 1 & - \\
\hline
\end{tabular}

Keterangan : ppm : part per million (mg/l) ; Tanda (-) : tidak memunculkan daun pada 12 MST 
Tabel 5. Pengaruh media tanam dan konsentrasi BAP terhadap saat muncul akar Anthurium hasil multiplikasi secara in vitro

\begin{tabular}{ccccc}
\hline \multirow{2}{*}{ Media dasar } & \multirow{2}{*}{ Ulangan } & \multicolumn{3}{c}{ Saat muncul akar } \\
\cline { 3 - 5 } & & BAP 0 ppm & BAP 2 ppm & BAP 4 ppm \\
\hline \multirow{2}{*}{ MS } & 1 & 2 MST & - & - \\
& 2 & 5 MST & - & 3 MST \\
& 3 & - & - & 7 MST \\
\hline \multirow{2}{*}{ N2 } & 1 & - & - & - \\
& 2 & - & - & - \\
& 3 & 3 MST & - & - \\
\hline \multirow{2}{*}{ SH } & 1 & - & 2 MST & 1 MST \\
& 2 & 7 MST & 2 MST & - \\
& 3 & 3 MST & - & - \\
\hline
\end{tabular}

Keterangan : $\quad$ MST $=$ minggu setelah tanam $; \mathrm{ppm}=$ part per million $(\mathrm{mg} / \mathrm{l}) \quad$ Tanda $(-):$ tidak muncul akar sampai dengan 12 MST

Tabel 6. Pengaruh media tanam dan konsentrasi BAP terhadap jumlah dan panjang akar Anthurium secara in vitro

\begin{tabular}{cccc}
\hline Perlakuan & Ulangan & Jumlah akar & Panjang akar \\
\hline \multirow{2}{*}{ MS-BAP 0 ppm } & 1 & 1 & $1,1 \mathrm{~mm}$ \\
& 2 & 1 & $1,2 \mathrm{~mm}$ \\
\hline \multirow{2}{*}{ MS-BAP 4 ppm } & 2 & 1 & $2 \mathrm{~mm}$ \\
& 3 & 1 & $4 \mathrm{~mm}$ \\
\hline \multirow{2}{*}{ N2-BAP 0 ppm } & 3 & 1 & $20 \mathrm{~mm}$ \\
\multirow{2}{*}{ SH-BAP 0 ppm } & 2 & 1 & $1,2 \mathrm{~mm}$ \\
& 3 & 1 & $5 \mathrm{~mm}$ \\
\hline \multirow{2}{*}{ SH-BAP 2 ppm } & 1 & 1 & $8 \mathrm{~mm}$ \\
\hline SH-BAP 4 ppm & 2 & 1 & $4 \mathrm{~mm}$ \\
\hline
\end{tabular}

Keterangan : ppm $=$ part per million $(\mathrm{mg} / \mathrm{l})$ 


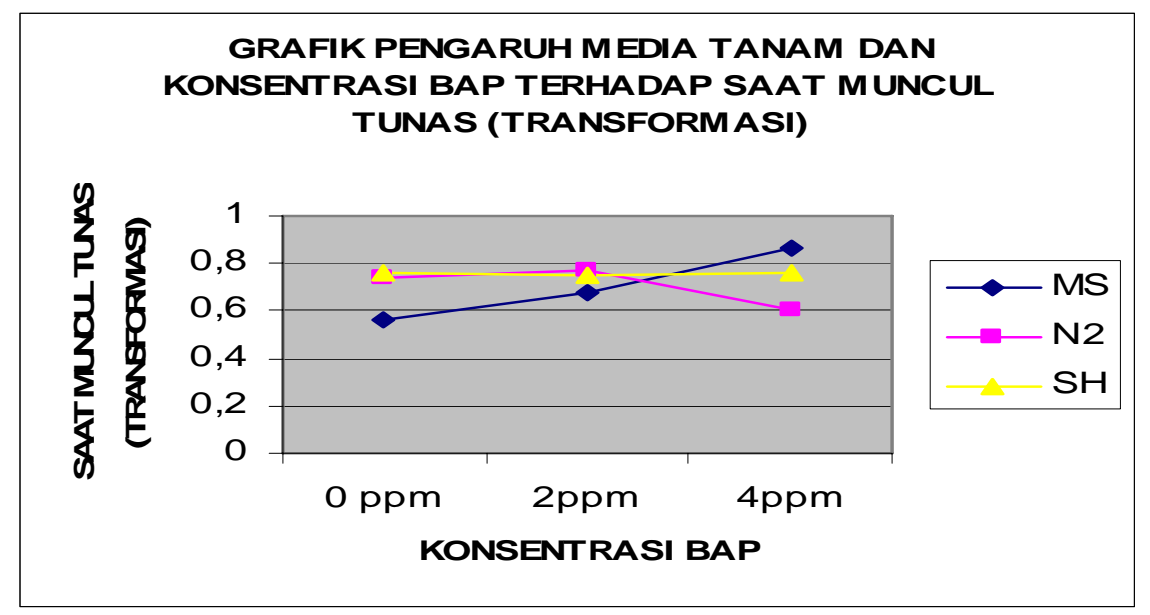

Gambar 1. Grafik pengaruh media tanam dan konsentrasi BAP terhadap saat muncul tunas Anthurium hasil multiplikasi secara in vitro

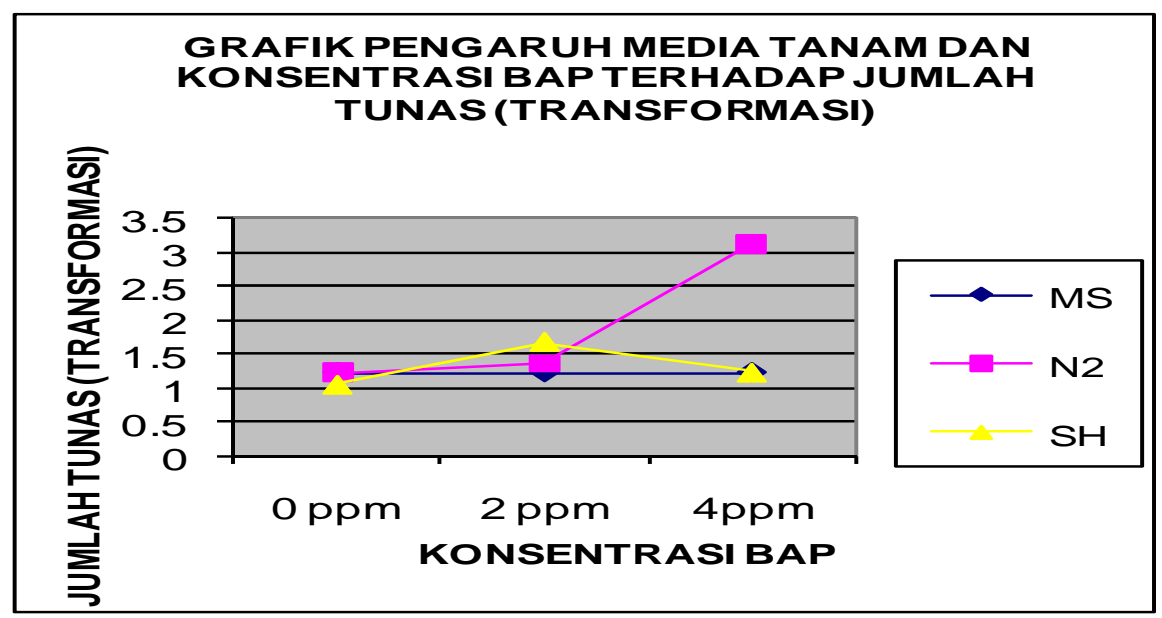

Gambar 2. Grafik pengaruh media tanam dan konsentrasi BAP terhadap jumlah tunas Anthurium hasil multiplikasi secara in vitro

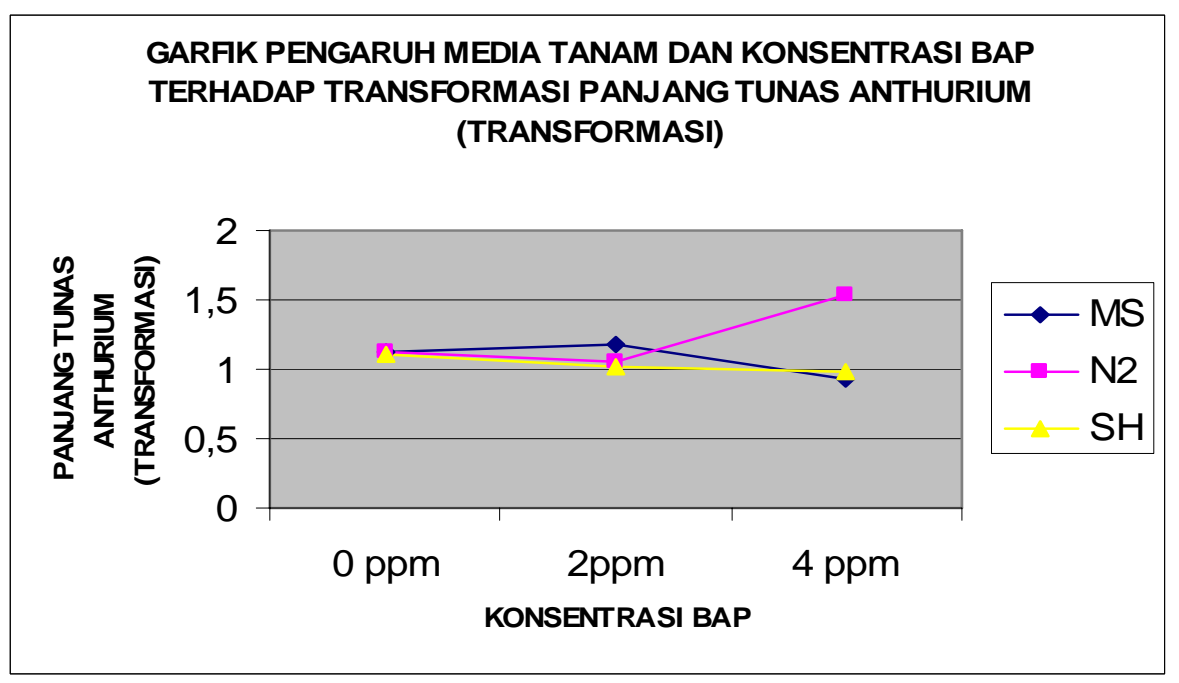

Gambar 3. Grafik pengaruh media tanam dan konsentrasi BAP terhadap panjang tunas Anthurium hasil multiplikasi secara in vitro 


\section{Jumlah Daun}

Hasil penelitian pada Tabel 4 menunjukkan bahwa jumlah daun yang lebih banyak didapatkan pada perlakuan medium MS 0 ppm BAP dan medium SH 0 ppm BAP (tanpa penambahan BAP). Pada medium $\mathrm{SH}$ tanpa penambahan BAP terbentuk 3 lembar daun, sedangkan pada MS tanpa BAP terbentuk 2 lembar daun. Dengan semakin meningkatnya konsentrasi BAP, semakin menurun jumlah daun yang terbentuk. Dari Tabel 4 ditunjukkan jumlah daun yang terbentuk hanya 1 lembar.

Berdasarkan Tabel 4, perlakuan medium SH dengan 0 BAP dapat memunculkan daun lebih banyak dibandingkan medium MS dengan 0 ppm BAP. Penyebab terjadinya hal tersebut diduga karena kandungan nutrisi medium $\mathrm{SH}$ lebih cocok untuk mendukung pertumbuhan daun pada kultur in vitro Anthurium. Menurut George dan Sherrington (1984) dan Gunawan (1988), medium SH cocok untuk mendukung pertumbuhan eksplan monokotil. Walaupun demikian, perlakuan Medium MS pada ketiga taraf perlakuan BAP dapat memunculkan daun walaupun jumlahnya sedikit. Hal ini disebabkan karena kandungan hara medium ini layak untuk memenuhi kebutuhan sel tanaman pada kultur jaringan (Wetter dan Constabel, 1991).

\section{Saat Muncul Akar}

Akar adalah organ tanaman yang berfungsi untuk menyerap nutrisi (unsur hara) baik makro maupun mikro dari media tumbuh untuk kemudian digunakan dalam proses tumbuh dan berkembangnya tanaman. Menurut Mattjik (2005), pembentukan akar pada kultur jaringan dapat terjadi langsung pada eksplan yang ditanam, baik dari jaringan, maupun dari kalus jika ke dalam media diberikan auksin yang mencukupi.

Dari Tabel 5, perlakuan pemberian ketiga konsentrasi BAP pada medium SH mampu memunculkan akar, namun hal tersebut tidak terjadi pada medium N2. Medium N2 hanya mampu memunculkan akar pada perlakuan 0 ppm BAP (tanpa penambahan BAP). Sedangkan pada medium MS perlakuan BAP yang mampu memunculkan akar ada pada konsentrasi 0 ppm dan $4 \mathrm{ppm}$. Dari hasil tersebut, diduga medium SH mempunyai kandungan hara makro dan mikro yang cocok untuk pertumbuhan akar pada kultur in vitro Anthurium. Adapun kemunculan akar pada pada medium N2 yang terhambat diduga karena pengaruh nitrogen/bentuk senyawa nitrogen dan rasio antara ammonium dengan nitrat pada medium yang belum dapat mempengaruhi terjadinya diferensiasi, pertumbuhan dan perkembangan eksplan atau pembentukan organ dengan cepat.

Menurut Pucchooa dan Sookum (2000) pengakaran eksplan pada kultur in vitro didapat dari medium tanpa penambahan BAP. Namun, variasi kemunculan akar terjadi pada penelitian ini. Pada medium SH, peningkatan konsentrasi BAP justru mampu mempercepat saat muncul akar (Tabel 5). Juga pada medium MS pemberian BAP 4 ppm dapat memunculkan akar, sementara pada 2 ppm BAP justru tidak memunculkan akar. Menurut Santoso dan Nursandi (2004), variasi tersebut dapat terjadi karena eksplan memiliki kepekaan sel yang berbeda terhadap rangsang yang diberikan, yakni ZPT, serta karena mekanisme kerja ZPT yang tidak konstan dalam jaringan eksplan sehingga menghasilkan respon yang tidak pasti (Pratiwi, 2004 cit Acima, 2006).

\section{Jumlah dan Panjang Akar}

Jumlah dan panjang akar penting bagi pertumbuhan eksplan pada kultur in vitro. Jumlah akar yang semakin banyak dan panjang bagus untuk penyerapan nutrisi dari media. Hal itu disebabkan karena semakin banyak dan semakin panjang akar maka bidang penyerapan nutrisi dari media akan semakin luas pula.

Tabel 6 menunjukkan bahwa jumlah akar yang muncul pada berbagai kombinasi perlakuan medium tanam dan konsentrasi BAP sama, yakni hanya mampu menumbuhkan 1 akar. Menurut Santoso dan Nursandi (2004), dalam kultur jaringan, penambahan sitokinin dapat menghambat pembentukan akar.

Pada penelitian ini, semua perlakuan yang mampu memunculkan akar yang ternyata hanya mampu menumbuhkan 1 akar. Menurut Prihatmani dan Mattjik (2004), akar yang terbentuk pada kultur in vitro masih dapat tumbuh dan bertambah seiring bertambahnya waktu.

Pada variabel panjang akar, akar terpanjang didapat pada perlakuan medium N2 dengan 0 ppm BAP (tanpa penambahan BAP) yakni sepanjang $20 \mathrm{~mm}$ dan akar terpendek didapat dari perlakuan MS 0 ppm BAP (tanpa penambahan BAP) yakni sepanjang $1,1 \mathrm{~mm}$. Diduga hal ini disebabkan oleh kombinasi medium tanam dan penambahan ZPT yang memberi efek yang berbeda-beda terhadap panjang akar. Keberhasilan kultur in vitro dipengaruhi oleh garam-garam mineral makro dan mikro yang terdapat dalam media dasar serta pengaruh ZPT yang diberikan 


\section{KESIMPULAN}

1. Interaksi media dan konsentrasi BAP menunjukkan hasil beda nyata terhadap jumlah dan panjang tunas Anthurium.

2. Perlakuan medium N2 dengan penambahan 4 ppm BAP menunjukkan jumlah tunas Anthurium terbanyak dan tunas Anthurium terpanjang.

3. Medium MS tanpa penambahan BAP memberikan saat muncul tunas Anthurium tercepat.

4. Saat muncul daun Anthurium tercepat ditunjukkan pada perlakuan MS dengan 2 ppm BAP, dan jumlah daun terbanyak ditunjukkan pada perlakuan medium SH tanpa penambahan BAP.

5. Saat muncul akar Anthurium tercepat ditunjukkan pada medium SH dengan penambahan 4 ppm BAP, dan akar terpanjang ditunjukkan pada perlakuan medium $\mathrm{N} 2$ tanpa penambahan BAP

\section{DAFTAR PUSTAKA}

Abidin, Z., 1994. Dasar-Dasar Pengetahuan Tentang Zat Pengatur Tumbuh. Penerbit Angkasa, Bandung.

Badriah, D., N. T. Mathius, T. Sutater, 1998. Tanggap Dua Kultivar Gladiol Terhadap Zat Pengatur Tumbuh pada Perbanyakan In vitro. J. Hort. 8(2): 1048-1059.

George, E. F. dan P. D. Sherrington, 1984. Plant Propagation by Tissue Culture. Exegetics Limited. England.

Gunawan, L. W., 1988. Teknik Kultur Jaringan Tumbuhan. PAU Bioteknologi IPB. Bogor.
Hoesen, D.S.H., 1998. Kultur Jaringan Kunir Putih (Kaempferia rotunda L). Berita Biologi. 4(4): 175-181.

Hoesen, D.S.H., 2001. Perbanyakan dan Penyimpanan Kultur Sambung Nyawa dengan teknik In vitro. Berita Biologi. 5(4): 397-385

Marlina, N., 2004. Teknik Perbanyakan Anthurium dengan Kultur Jaringan. www.pustakadeptan.go.id/publication/bt092049.pdf. Diakses tanggal 13 Februari 2006.

Mattjik, N. A., 2005. Peranan Kultur Jaringan Dalam Perbaikan Tanaman. Orasi Ilmiah Guru Besar IPB. FP IPB, Bogor.

Prihatmani, D dan N. A. Mattjik, 2004. Penggunaan Zat Pengatur Tumbuh NAA (Naphtalene Acetic Acid) dan BAP (6Benzil Amino Purine) serta Air Kelapa untuk Menginduksi Organogenesis Tanaman Anthurium (Anthurium andraeanum Linden ex Andre). Bul. Agron. 32(1): 20-25.

Pucchooa dan Sookum, 2000. Induced Mutation and In vitro Culture of Anthurium andraeanum.www.gov.mu /portal/sites/ncb/moa/farc/ presen/s1/ s1.3_files/frame.htm. Diakses tanggal 27 Februari 2007.

Triatminingsih, R., Karsinah, H. Subakti, L. Fitrianingsih, 2003. Kultur In vitro Biji Duku. J. Hort. 13(2): 77-81.

Wetter, L. R. dan F. Constabel, 1991. Metode Kultur Jaringan Tanaman. ITB, Bandung.

Yelnititis, N. Bermawie, dan Syafaruddin, 1999. Perbanyakan Klon Lada Varietas Panniyur secara In vitro. Jurnal Littri. 5(3): 109-114.

Yusnita, 2003. Kultur Jaringan Cara Memperbanyak Tanaman Secara In vitro. Agromedia Pustaka, Jakarta 